\title{
Down-regulation of microsomal prostaglandin E2 synthase-1 in the infrapatellar fat pad of osteoarthritis patients with hypercholesterolemia
}

Manabu Mukai, Kentaro Uchida* D, Shotaro Takano, Dai Iwase, Jun Aikawa, Gen Inoue, Masayuki Miyagi and Masashi Takaso

\begin{abstract}
Background: While epidemiological studies have reported a potential role for hypercholesterolemia (HCE) in osteoarthritis (OA), the association between HCE and OA has yet to be clarified. Adipose tissue is a primary locus for cholesterol metabolism and the presence of HCE reportedly causes adipose dysfunction. The knee joint contains adipose tissue in the form of the infrapatellar fat pad (IPFP), which has been shown to contribute to the pathophysiology of OA in the knee via the secretion of inflammatory mediators. However, the effect of HCE on the expression of inflammatory mediators in the IPFP has not been elucidated.

Methods: IPFP and synovial tissues (ST) were extracted from 145 subjects with OA, diagnosed by radiography, during total knee arthroplasty. OA patients were divided into three groups according to their total cholesterol levels (Desirable, Borderline high and High) based on the National Cholesterol Education Program Adult Treatment Panel III (NCEPATP III). We examined the expression of cyclooxygenase-2 (COX-2), microsomal prostaglandin E synthase-1 (mPGES1), tumor necrosis factor (TNF)- $\alpha$, interleukin (IL)-1 $\beta$, and IL-6 using real-time polymerase chain reaction and compared results among the Desirable, Borderline high and High groups.

Results: The mRNA expression levels of TNF- $a, I L-1 \beta$, and IL- 6 in ST and the IPFP were not significantly different among the three groups. COX-2 mRNA expression in ST and IPFP was likewise not different among the three groups. While the mRNA expression level of MPGES1 in ST was also not significantly different, that of mPGES1 in the IPFP was significantly lower in the High group than in the Desirable and Borderline high groups.
\end{abstract}

Conclusion: mRNA levels of mPGES-1 are reduced in the IPFP of knee OA patients with HCE. Additional studies are need to clarify the effect of mPGES-1 down-regulation in OA pathology.

Keywords: Hypercholesterolemia, Infrapatellar fat pad, Microsomal prostaglandin E2 synthase-1

\section{Background}

Numerous reports have suggested that osteoarthritis (OA), rather than simply being a mechanical stress-related joint disorder, is also a metabolic syndrome wherein various risk factors function together to cause disease initiation and/or development. While hypercholesterolemia (HCE) is an established risk factor for cardiovascular disorders, epidemiological studies have also reported a

\footnotetext{
* Correspondence: kuchida@med.kitasato-u.ac.jp

Department of Orthopedic Surgery, Kitasato University School of Medicine, 1-15-1 Minami-ku Kitasato, Sagamihara City, Kanagawa 252-0374, Japan
}

possible role for HCE in OA [1-4]. HCE is associated with both unilateral and bilateral knee OA independently of obesity [5]. High serum cholesterol levels are associated with both knee and generalized OA [4]. However, the association between HCE and OA has yet to be clarified.

Adipose tissue is a primary locus for cholesterol metabolism, and the presence of HCE reportedly causes adipose dysfunction. The knee joint contains adipose tissue in the form of the infrapatellar fat pad (IPFP), which is intracapsularly and extrasynovially positioned near the synovium, cartilage and bone [6]. Its location within the

(C) The Author(s). 2018 Open Access This article is distributed under the terms of the Creative Commons Attribution 4.0 International License (http://creativecommons.org/licenses/by/4.0/), which permits unrestricted use, distribution, and 
joint makes it possible for the IPFP to play a role in the pathophysiology of OA in the knee via the secretion of inflammatory signals such as interleukin (IL)-6 and tumor necrosis factor-a (TNF- $\alpha$ ) [7, 8]. However, the effect of HCE on inflammatory cytokine expression in the IPFP has not been elucidated.

Prostaglandin E2 (PGE2) is synthesized by the arachidonic acid cascade, which is formed by the concerted action of cyclooxygenases-2 (COX-2) and the specific terminal synthase microsomal prostaglandin E2 synthase-1 (mPGES-1) $[9,10]$. PGE2 is a major PG implicated in inflammatory reactions [11-13] and contributes to adipose tissue metabolism [14]. The IPFP releases higher levels of PGE2 than subcutaneous adipose tissue in vitro [15]. Several studies have reported that mPGES-1 expression and PGE2 production are lower in human adipocytes derived from obese patients and adipose tissue harvested from high fat diet (HFD) mice than those from their non-obese and control counterparts, respectively [16]. Investigation of the arachidonic acid cascade in the IPFP of OA patients with HCE may unveil a possible mechanism for HCE in the initiation and/or development of OA.

Here, we examined the expression levels of various inflammatory meditators in the IPFP of OA patients with HCE.

\section{Methods}

We studied samples from 31 men and 114 women (mean \pm standard deviation $[\mathrm{SD}]$ age $=73.2 \pm 7.7$ years; body mass index $\left.[\mathrm{BMI}]=26.2 \pm 4.2 \mathrm{~kg} / \mathrm{m}^{2}\right)$ with knee OA diagnosed by radiography (unilateral Kellgren/Lawrence grades $2[n=$ $3 / 145,2 \%], 3$ [ $n=56 / 145,40 \%]$, and $4[n=86 / 145,58 \%]$; serum total cholesterol $(\mathrm{TCHO}):=207 \pm 39 \mathrm{mg} / \mathrm{dl}$; serum triglycerides $[\mathrm{TG}]=129 \pm 70 \mathrm{mg} / \mathrm{dl}$; and serum hemoglobin $1 \mathrm{Ac}[\mathrm{HbA} 1 \mathrm{c}]=6.0 \pm 0.5 \%$ ). All participants received total knee arthroplasty at our institution from March 2015 to June 2017. IPFP and synovial tissue (ST) specimens were extracted from each operated knee during the surgery. A piece of each IPFP and ST specimen was instantly frozen in liquid nitrogen at $-80^{\circ} \mathrm{C}$ until RNA extraction.

This study was approved by the Ethics Review Board of Kitasato University (reference number: KMEO B13113). Informed consent was obtained from all participants the day before surgery for participation in this study and the extraction and use of their ST.

\section{Real-time (RT)-polymerase chain reaction (PCR) analysis}

OA patients were divided into three groups according to their TCHO levels (Desirable, Borderline high and High) based on the National Cholesterol Education Program Adult Treatment Panel III (NCEP ATP III) (Table 1). Clinical characteristics of patients in each group are shown in Table 2. Total RNA extraction, cDNA synthesis and real-time PCR methods were conducted as described previously [17]. Primers used are listed in
Table 1 NCEP ATP III classification of total cholesterol

\begin{tabular}{ll}
\hline Total cholesterol $(\mathrm{mg} / \mathrm{dl})$ & Classification \\
\hline$<200$ & Desirable \\
$200-239$ & Borderline high \\
$\geq 240$ & High \\
\hline
\end{tabular}

Table 3. We examined the expression of COX-2, mPGES1, TNF- $\alpha$, IL-1 $\beta$, and IL- 6 in the IPFP and ST using real-time PCR and compared these among the three groups. We also divided the patients into three groups (normal, overweight, obese) based on the World Health Organization Body Mass Index (BMI) classification (Additional files 1 and 2: Tables S1 and S2). However, we observed no differences in COX-2 or mPGES1 expression in the IPFP among the BMI groups (Additional file 3: Figure S1).

\section{Statistical analysis}

Statistical analysis was performed using the SPSS 19.0 statistical package. Analysis of variance and Tamhane's T2 test were used for continuous variables, and the Fisher exact test was used for categorical variables. A $p$ value of 0.05 was considered statistically significant.

\section{Results}

Patients divided into three groups according to their TCHO based on ATP III showed no differences in age, male/female ratio, KL grade ratio, BMI, TG, or $\mathrm{HbA1c}$ (Table 1). The expression levels of TNF- $\alpha$, IL-1 $\beta$, and IL-6 in ST and the IPFP were not significantly different among the three groups (Fig. 1a-f). COX-2 mRNA expression in ST and the IPFP was likewise not different among the three groups (Fig. 2a, c). While the mRNA expression level of mPGES1 in ST was also not significantly different (Fig. 2b), that of mPGES1 in the IPFP was significantly lower in the High group than the Desirable and Borderline high groups (Fig. 2d).

Table 2 Clinical characteristics of patients classified into three groups according to total cholesterol level

\begin{tabular}{lllll}
\hline & $\begin{array}{l}\text { Desirable } \\
(n=60)\end{array}$ & $\begin{array}{l}\text { Borderline high } \\
(n=61)\end{array}$ & $\begin{array}{l}\text { High } \\
(n=24)\end{array}$ & $P$ \\
\hline Age (years) & $73.5 \pm 7.3$ & $72.9 \pm 8.6$ & $73.6 \pm 6.8$ & 0.912 \\
Male/Female, $\mathrm{n}$ & $16 / 44$ & $11 / 50$ & $4 / 20$ & 0.453 \\
$\mathrm{KL}(2 / 3 / 4)$ & $1 / 24 / 35$ & $1 / 24 / 36$ & $1 / 8 / 15$ & 0.861 \\
$\mathrm{BMI}\left(\mathrm{kg} / \mathrm{m}^{2}\right)$ & $26.6 \pm 4.2$ & $26.2 \pm 4.4$ & $25.1 \pm 3.5$ & 0.360 \\
$\mathrm{TCHO}(\mathrm{mg} / \mathrm{dl})$ & $173 \pm 22$ & $218 \pm 12$ & $267 \pm 32$ & $<0.001$ \\
$\mathrm{TG}(\mathrm{mg} / \mathrm{dl})$ & $124 \pm 83$ & $127 \pm 49$ & $145 \pm 81$ & 0.436 \\
$\mathrm{HbA}$ (c $(\%)$ & $6.0 \pm 0.5$ & $6.0 \pm 0.5$ & $5.8 \pm 0.3$ & 0.287 \\
\hline
\end{tabular}

All values indicate mean \pm standard deviation unless otherwise indicated $K L$ Kellgren and Lawrence grade, $B M I$ body mass index, $T C H O$ total cholesterol, TG triglyceride, $\mathrm{HbA1C}$ hemoglobin A1c 
Table 3 Primer sequences

\begin{tabular}{|c|c|c|}
\hline Primer & Sequence $\left(5^{\prime}-3^{\prime}\right)$ & Product size $(b p)$ \\
\hline COX-2-F & TGGCTGAGGGAACACAACAG & 74 \\
\hline $\mathrm{COX}-2-\mathrm{R}$ & AACAACTGCTCATCACCCCA & \\
\hline mPGES1-F & GGAGACCATCTACCCCTTCCT & 81 \\
\hline mPGES1-R & AAGTGCATCCAGGCGACAAA & \\
\hline TNF-a-F & CCCATCCCATCTTCCACAGG & 74 \\
\hline TNF-a-R & GGTGGTCTTATCCCCAACCC & \\
\hline$I L-1 \beta-F$ & GTACCTGTCCTGCGTGTTGA & 153 \\
\hline$I L-1 \beta-R$ & GGGAACTGGGCAGACTCAAA & \\
\hline IL-6-F & GAGGAGACTTGCCTGGTGAAA & 199 \\
\hline IL-6-R & TGGCATTTGTGGTTGGGTCA & \\
\hline GAPDH-F & TGTTGCCATCAATGACCCCTT & 202 \\
\hline GAPDH-R & CTCCACGACGTACTCAGCG & \\
\hline
\end{tabular}

\section{Discussion}

Several studies have reported that inflammatory cytokine levels in the IPFP are affected by obesity. Elevated TNF- $\alpha$ expression has been observed in the IPFP of HFD mice [18]. Moreover, TNF- $\alpha$ levels are increased in the fat-conditioned medium (FCM) obtained from the IPFP of patients with high BMI $(\mathrm{BMI}>30)$ compared to that from patients with low BMI $(\mathrm{BMI} \leq 25)[19]$. We observed no difference in the mRNA expression of TNF- $\alpha$, IL-1 $\beta$, or IL-6 among Desirable, Borderline high and High cholesterol groups. HCE in HFD mice is commonly accompanied by obesity and hyperlipidemia, and HFD models are used to examine the development of obesity. Taken together, our results and those of previous studies suggest that elevated inflammatory cytokine production in the IFPF may be affected by BMI rather than HCE.

Several studies have reported that the arachidonic cascade is altered in several metabolic conditions [14, 16]. Cultured adipocytes from obese rats release PGE at lower rates than those from lean rats [14]. Further, a higher degree of adipocyte differentiation in culture is correlated with reduced basal PGE synthesis for cells derived from obese compared to lean rats [14]. The release of PGE2 by adipocytes from human visceral and subcutaneous abdominal adipose tissues is markedly reduced in excessively obese individuals $\left(\mathrm{BMI}>45 \mathrm{~kg} / \mathrm{m}^{2}\right.$ ). The expression of mPGES1 is selectively reduced in WAT of HFD mice [16]. We similarly observed a decrease in the expression of mPGES1 in the IPFP of OA patients with HCE, although no difference was observed in mPGES1 levels among normal, overweight, and obese patients. HCE may therefore affect the production of PGE2 in the IPFP.

A number of studies on articular cartilage or chondrocytes have concluded that the inhibition or stimulation of PGE2 concentration by various molecules or factors indicates chondro-protective or chondro-destructive effects by those molecules or factors, respectively [20]. PGE2 has similarly been implicated in inflammation and

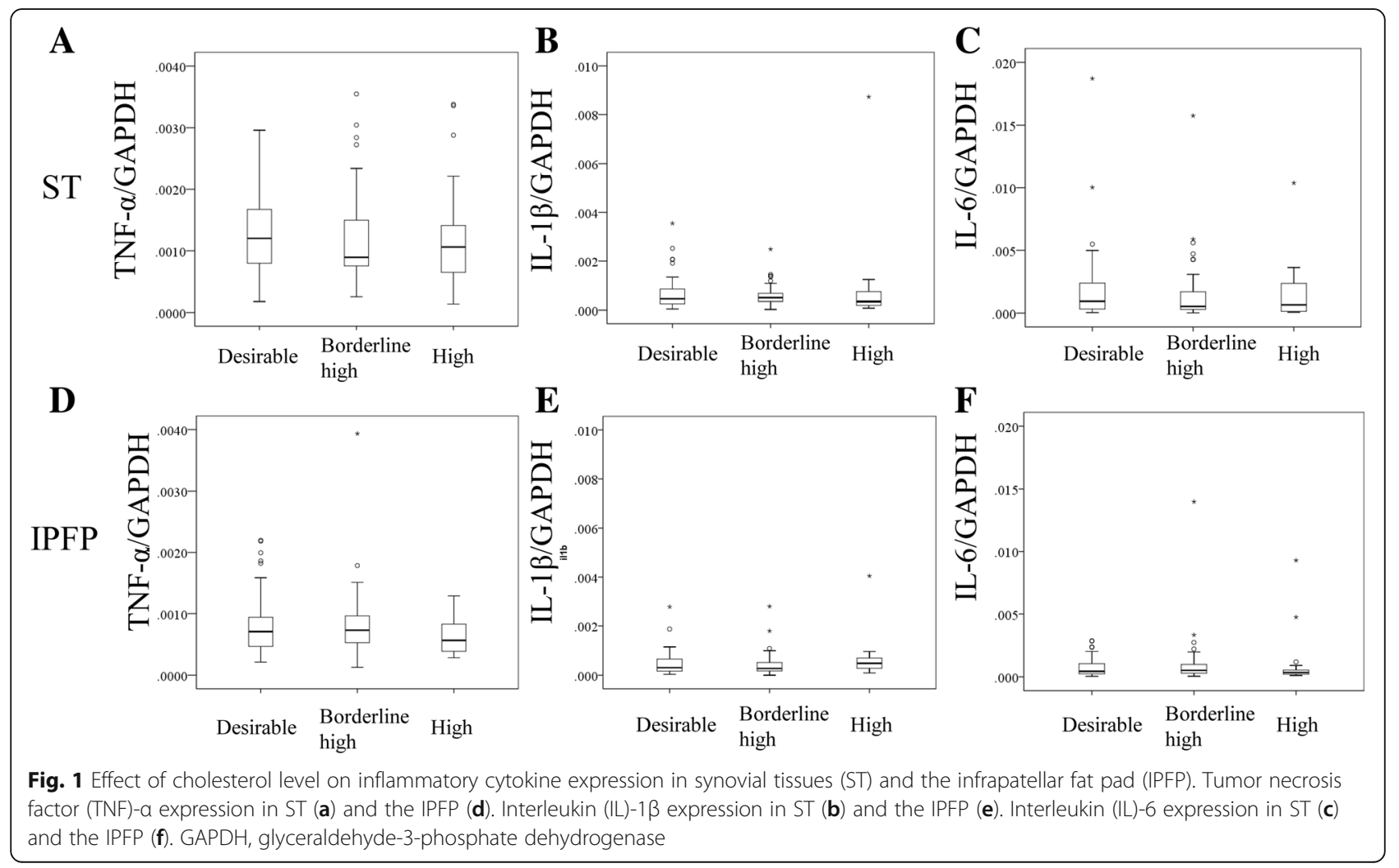



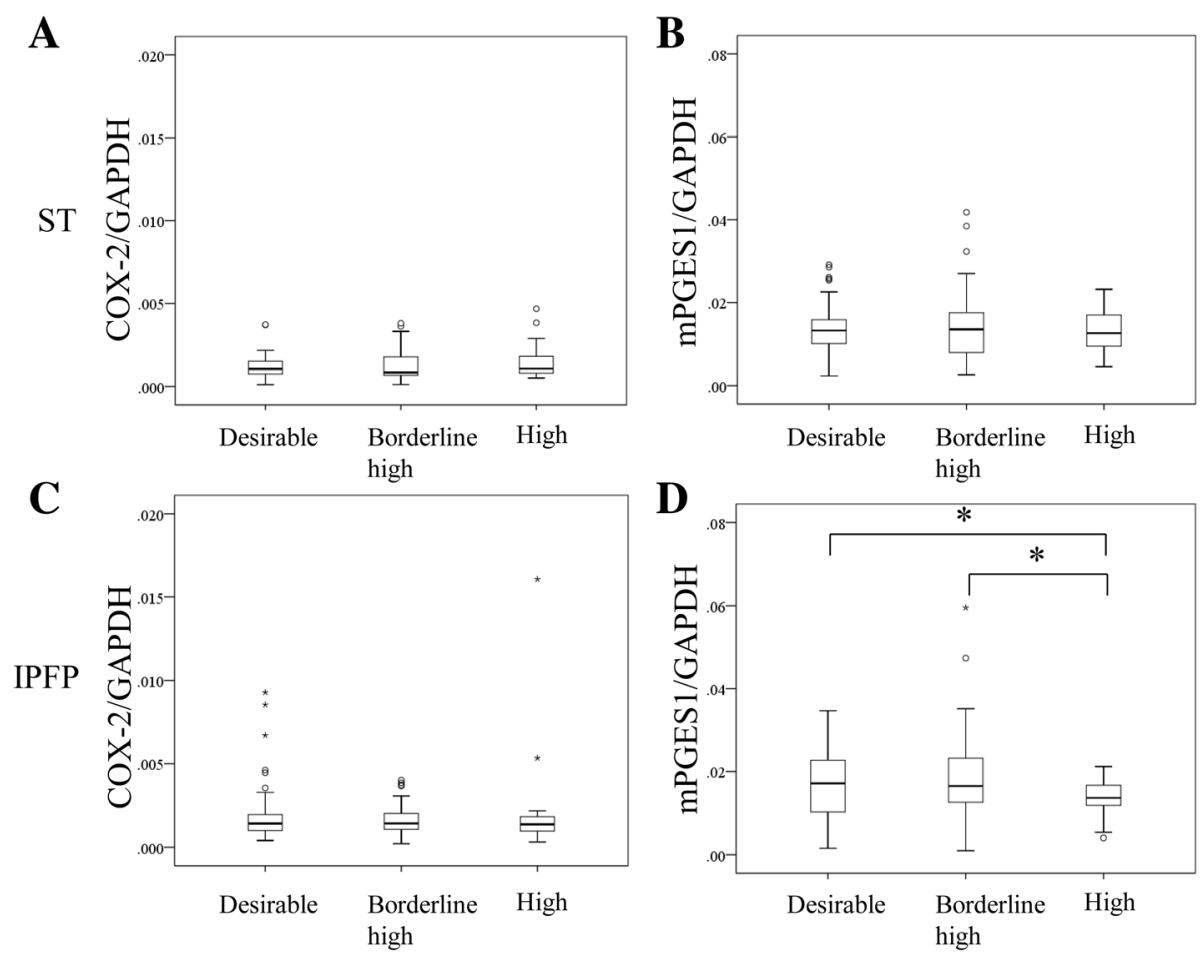

Fig. 2 Effect of cholesterol level on cyclooxygenase-2 (COX-2) and microsomal prostaglandin E synthase-1 (mPGES1) expression in synovial tissues (ST) and the infrapatellar fat pad (IPFP). COX-2 expression in ST (a) and the IPFP (c). mPGES1 expression in ST (b) and the IPFP (d). GAPDH, glyceraldehyde-3-phosphate dehydrogenase

joint destruction in animal arthritis models [21, 22]. mPGES-1 expression by inflammatory stimuli correlates with increased PGE2 production [23]. mPGES-1 is located in cartilage in OA patients [24]. Further, mPGES-1 mRNA and protein levels in OA cartilage were increased compared to normal cartilage [24]. Recent studies have reported that inhibition of mPGES1 relieves pain in mice and canine OA models, suggesting that MPGES1 might be a therapeutic target in OA $[13,25,26]$. In contrast, a few reports have shown that continuous inhibition of PGE2 using nonsteroidal anti-inflammatory drugs accelerates OA progression [27, 28]. Moreover, PGE2 reportedly has both anabolic and catabolic functions in chondrocytes $[29,30]$. Continuous suppression of mPGES-1 in the IPFP of HCE patients may reduce PGE2 production. Further studies are required to confirm this and to clarify how this affects the knee joint.

There are two main limitations of this study. First, we did not examine the expression levels of inflammatory mediators in a control, non-OA patient population; further studies comparing $\mathrm{OA}$ and non-OA populations are needed to confirm our findings. Second, we did not examine the relationship between OA pathology and mPGES1 expression.

\section{Conclusions}

Expression levels of mPGES-1 are reduced in the IPFP of knee OA patients with HCE. Additional studies are needed to clarify the effect of mPGES-1 down-regulation in OA pathology.

\section{Additional files}

Additional file 1: Table S1. World Health Organization Body Mass Index (BMI) classification. (DOCX $14 \mathrm{~kb}$ )

Additional file 2: Table S2. Clinical characteristics of patients classified into three groups according to their body mass index. (DOCX $15 \mathrm{~kb}$ )

Additional file 3: Figure S1. Effect of body mass index on cyclooxygenase-2 (COX-2) and microsomal prostaglandin E synthase-1 (MPGES1) expression in synovial tissues (ST) and the infrapatellar fat pad (IPFP). OA patients $(n=145)$ were divided into three groups (normal, overweight, obese) according to the WHO BMI classification. We examined the expression of COX-2 and MPGES1 in the IPFP and ST using realtime PCR and compared these among normal, overweight, and obese groups. There were no differences in COX-2 or mPGES1 expression in the IPFP or in ST among the groups. GAPDH, glyceraldehyde-3-phosphate dehydrogenase. (TIFF $1428 \mathrm{~kb}$ )

\section{Abbreviations}

BMI: Body mass index; COX-2: Cyclooxygenase-2; FCM: Fat-conditioned medium; GAPDH: Glyceraldehyde-3-phosphate dehydrogenase;

HCE: Hypercholesterolemia; HFD: High fat diet; IL-1 $\beta$ : Interleukin-1 $\beta$; IL6: Interleukin-6; mPGES-1: Microsomal prostaglandin E synthase-1; NCEP ATP III: National Cholesterol Education Program Adult Treatment Panel III; OA: Osteoarthritis; PCR: Polymerase chain reaction; PGE2: Prostaglandin E2; TNF-a: Tumor necrosis factor-a

Acknowledgements

We thank Ms. Yuko Onuki for her assistance with real time PCR analysis. 


\section{Funding}

This investigation was supported in part by the Uehara Memorial Foundation; a Kitasato University Research Grant for Young Researchers; and research grants from the Parents' Association of Kitasato University School of Medicine.

\section{Availability of data and materials}

The datasets supporting the conclusions of this article are included within the article.

\section{Authors' contributions}

KU, GI and MT designed the study and analyzed the data. MM (Mukai) and KU wrote the manuscript. ST, DI, Jl, and MM (Miyagi) contributed to data collection. All authors read and approved the final manuscript.

\section{Ethics approval and consent to participate}

This study was approved by the Ethics Review Board of Kitasato University (reference number: KMEO B13-113). Consent was obtained from the participants for participation in this study and the extraction and use of their ST.

\section{Competing interests}

The authors declare that they have no competing interests.

\section{Publisher's Note}

Springer Nature remains neutral with regard to jurisdictional claims in published maps and institutional affiliations.

\section{Received: 20 February 2018 Accepted: 29 May 2018}

\section{Published online: 13 June 2018}

\section{References}

1. Bierma-Zeinstra SM, Koes BW. Risk factors and prognostic factors of hip and knee osteoarthritis. Nat Clin Pract Rheumatol. 2007;3(2):78-85.

2. Dahaghin S, Bierma-Zeinstra SM, Koes BW, Hazes JM, Pols HA. Do metabolic factors add to the effect of overweight on hand osteoarthritis? The Rotterdam Study. Ann Rheum Dis. 2007;66(7):916-20.

3. Martins IJ, Hone E, Foster JK, Sunram-Lea SI, Gnjec A, Fuller SJ, Nolan D, Gandy SE, Martins RN. Apolipoprotein E, cholesterol metabolism, diabetes, and the convergence of risk factors for Alzheimer's disease and cardiovascular disease. Mol Psychiatry. 2006;11(8):721-36.

4. Al-Arfaj AS. Radiographic osteoarthritis and serum cholesterol. Saudi Med J. 2003;24(7):745-7.

5. Hart DJ, Doyle DV, Spector TD. Association between metabolic factors and knee osteoarthritis in women: the Chingford study. J Rheumatol. 1995;22(6):1118-23.

6. Gallagher J, Tierney P, Murray P, O'Brien M. The infrapatellar fat pad: anatomy and clinical correlations. Knee Surg Sports Traumatol Arthrosc. 2005;13(4):268-72.

7. Hotamisligil GS, Arner P, Caro JF, Atkinson RL, Spiegelman BM. Increased adipose tissue expression of tumor necrosis factor-alpha in human obesity and insulin resistance. J Clin Invest. 1995;95(5):2409-15.

8. Mohamed-Ali V, Goodrick S, Rawesh A, Katz DR, Miles JM, Yudkin JS, Klein S, Coppack SW. Subcutaneous adipose tissue releases interleukin-6, but not tumor necrosis factor-alpha, in vivo. J Clin Endocrinol Metab. 1997;82(12):4196-200.

9. Jakobsson PJ, Thoren S, Morgenstern R, Samuelsson B. Identification of human prostaglandin E synthase: a microsomal, glutathione-dependent, inducible enzyme, constituting a potential novel drug target. Proc Natl Acad Sci U S A. 1999;96(13):7220-5

10. Ouellet M, Falqueyret JP, Ear PH, Pen A, Mancini JA, Riendeau D, Percival MD. Purification and characterization of recombinant microsomal prostaglandin E synthase-1. Protein Expr Purif. 2002;26(3):489-95.

11. Claveau D, Sirinyan M, Guay J, Gordon R, Chan CC, Bureau Y, Riendeau D, Mancini JA. Microsomal prostaglandin E synthase-1 is a major termina synthase that is selectively up-regulated during cyclooxygenase-2dependent prostaglandin E2 production in the rat adjuvant-induced arthritis model. J Immunol. 2003;170(9):4738-44.

12. Narumiya S, Sugimoto $Y$, Ushikubi F. Prostanoid receptors: structures, properties, and functions. Physiol Rev. 1999;79(4):1193-226.

13. Trebino CE, Stock JL, Gibbons CP, Naiman BM, Wachtmann TS, Umland JP, Pandher K, Lapointe JM, Saha S, Roach ML, Carter D, Thomas NA, Durtschi BA, McNeish JD, Hambor JE, Jakobsson PJ, Carty TJ, Perez JR, Audoly LP. Impaired inflammatory and pain responses in mice lacking an inducible prostaglandin E synthase. Proc Natl Acad Sci U S A. 2003;100(15):9044-9.
14. Gaskins HR, Hausman DB, Martin RJ, Hausman GJ. Evidence for abnormal prostaglandin synthesis in obese Zucker rat adipose cell cultures. J Nutr. 1989;119(3):458-62.

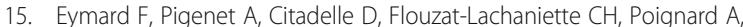
Benelli C, Berenbaum F, Chevalier X, Houard X. Induction of an inflammatory and prodegradative phenotype in autologous fibroblast-like synoviocytes by the infrapatellar fat pad from patients with knee osteoarthritis. Arthritis Rheum. 2014;66(8):2165-74.

16. Hetu PO, Riendeau D. Down-regulation of microsomal prostaglandin E2 synthase-1 in adipose tissue by high-fat feeding. Obesity. 2007;15(1):60-8.

17. Minatani A, Uchida K, Inoue G, Takano S, Aikawa J, Miyagi M, Fujimaki H, Iwase D, Onuma K, Matsumoto T, Takaso M. Activation of calcitonin generelated peptide signaling through the prostaglandin E2-EP1/EP2/EP4 receptor pathway in synovium of knee osteoarthritis patients. J Orthop Surg Res. 2016:11(1):117.

18. Iwata M, Ochi H, Hara Y, Tagawa M, Koga D, Okawa A, Asou Y. Initial responses of articular tissues in a murine high-fat diet-induced osteoarthritis model: pivotal role of the IPFP as a cytokine fountain. PLoS One. 2013;8(4):e60706.

19. de Jong AJ, Klein-Wieringa IR, Andersen SN, Kwekkeboom JC, Herb-van TL, de Lange-Brokaar BJE, van Delft D, Garcia J, Wei W, van der Heide HJ Bastiaansen-Jenniskens YM, van Osch GJVM, Zuurmond AM, StojanovicSusulic V, Nelissen RGHH, Toes REM, Kloppenburg M, loan-Facsinay A. Lack of high BMI-related features in adipocytes and inflammatory cells in the infrapatellar fat pad (IFP). Arthritis Res Ther. 2017:19(1):186.

20. Nah SS, Choi IY, Lee CK, Oh JS, Kim YG, Moon HB, Yoo B. Effects of advanced glycation end products on the expression of COX-2, PGE2 and NO in human osteoarthritic chondrocytes. Rheumatology. 2008;47(4):425-31.

21. Honda T, Segi-Nishida E, Miyachi Y, Narumiya S. Prostacyclin-IP signaling and prostaglandin E2-EP2/EP4 signaling both mediate joint inflammation in mouse collagen-induced arthritis. J Exp Med. 2006;203(2):325-35.

22. McCoy JM, Wicks JR, Audoly LP. The role of prostaglandin E2 receptors in the pathogenesis of rheumatoid arthritis. J Clin Invest. 2002;110(5):651-8.

23. Kojima F, Naraba H, Sasaki Y, Okamoto R, Koshino T, Kawai S. Coexpression of microsomal prostaglandin E synthase with cyclooxygenase-2 in human rheumatoid synovial cells. J Rheumatol. 2002:29(9):1836-42

24. Li X, Afif H, Cheng S, Martel-Pelletier J, Pelletier JP, Ranger P, Fahmi H. Expression and regulation of microsomal prostaglandin E synthase-1 in human osteoarthritic cartilage and chondrocytes. J Rheumatol. 2005;32(5):887-95.

25. Dray A, Read SJ. Arthritis and pain. Future targets to control osteoarthritis pain. Arthritis Res Ther. 2007;9(3):212.

26. Robertson-Plouch C, Stille JR, Liu P, Malcolm S, Brown D, Warner M, Fisher MJ. A randomized, placebo-controlled, proof-of-concept efficacy study of a microsomal prostaglandin E synthase-1 (MPGES1) inhibitor and a prostaglandin E receptor (EP4) antagonist in the treatment of canine osteoarthritis pain. Ann Rheum Dis. 2017;76(Suppl 2):765-6.

27. Rashad S, Revell P. Hemingway A, Low F, Rainsford K, Walker F. Effect of non-steroidal anti-inflammatory drugs on the course of osteoarthritis. Lancet. 1989;2(8662):519-22.

28. Reijman M, Bierma-Zeinstra SM, Pols HA, Koes BW, Stricker BH, Hazes JM. Is there an association between the use of different types of nonsteroidal antiinflammatory drugs and radiologic progression of osteoarthritis? The Rotterdam Study. Arthritis Rheum. 2005;52(10):3137-42.

29. Amin AR, Dave M, Attur M, Abramson SB. COX-2, NO, and cartilage damage and repair. Curr Rheumatol Rep. 2000;2(6):447-53.

30. Goldring MB, Berenbaum $F$. The regulation of chondrocyte function by proinflammatory mediators: prostaglandins and nitric oxide. Clin Orthop Relat Res. 2004:(427 S):S37-46. 